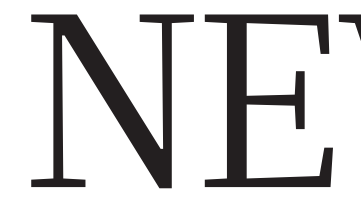

PUBLIC HEALTH Escalating the fight against childhood diarrhoea $\mathbf{p . 5 1 9}$
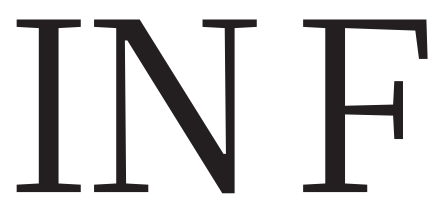

ETHICS Aboriginal

PHrsics Improbable neutrino result prompts hunt for cause $\mathbf{p . 5 2 0}$ genome addresses consent issues $\mathbf{p . 5 2 2}$

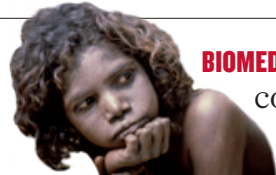

BIOMEDICINE Four fixes for costly, failure-prone clinical trials $\mathbf{p . 5 2 6}$

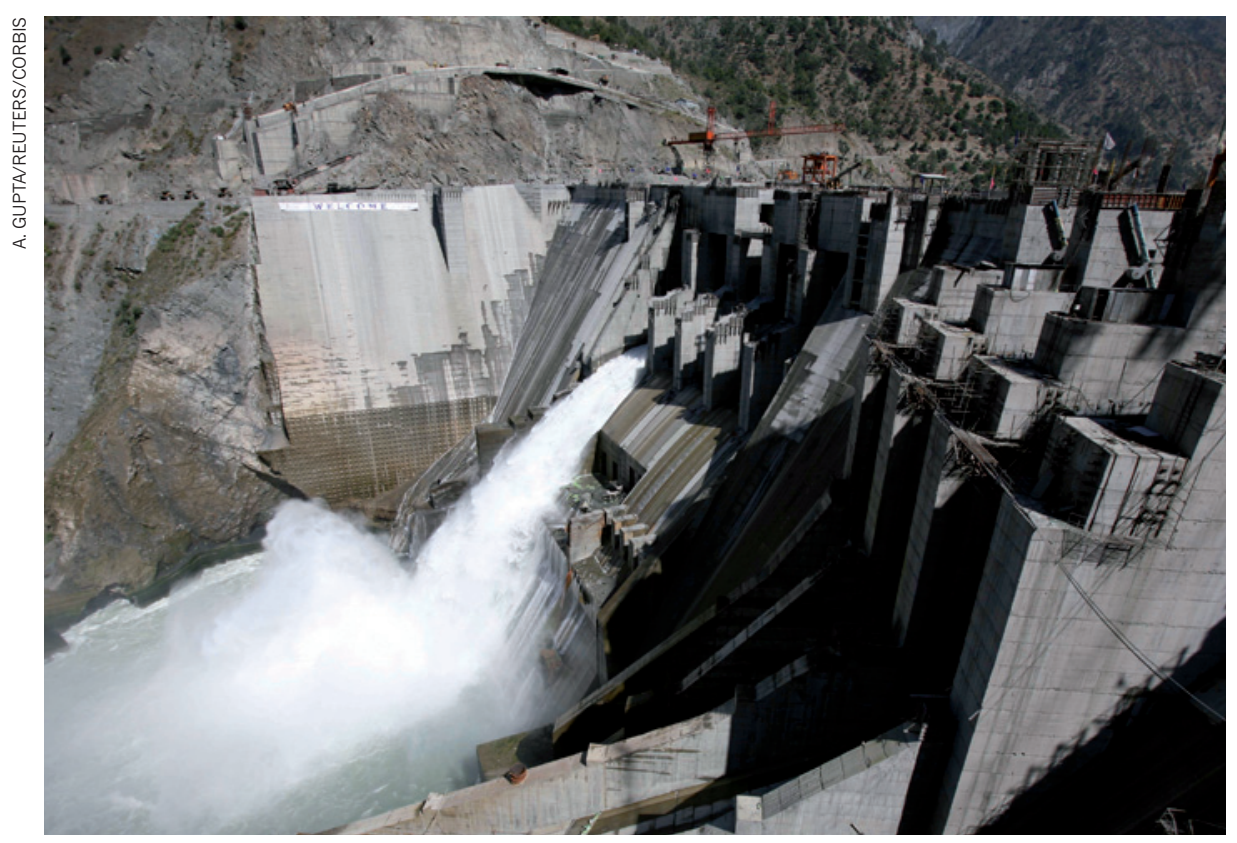

Indian carbon-credit claims — such as those for the Baglihar Dam (above) - are under scrutiny.

\title{
Clean-energy credits tarnished
}

\section{WikiLeaks reveals that most Indian claims are ineligible.}

\section{BY QUIRIN SCHIERMEIER}

A $s$ the world gears up for the next round of United Nations climate-change negotiations in Durban, South Africa, in November, evidence has emerged that a cornerstone of the existing global climate agreement, the international greenhouse-gas emissions-trading system, is seriously flawed.

Critics have long questioned the usefulness of the Clean Development Mechanism (CDM), which was established under the Kyoto Protocol. It allows rich countries to offset some of their carbon emissions by investing in climatefriendly projects, such as hydroelectric power and wind farms, in developing countries. Verified projects earn certified emission reductions
(CERs) - carbon credits that can be bought and sold, and count towards meeting rich nations' carbon-reduction targets.

But a diplomatic cable published last month by the WikiLeaks website reveals that most of the CDM projects in India should not have been certified because they did not reduce emissions beyond those that would have been achieved without foreign investment. Indian officials have apparently known about the problem for at least two years.

"What has leaked just confirms our view that in its present form the CDM is basically a farce," says Eva Filzmoser, programme director of CDM Watch, a Brussels-based watchdog organization. The revelations imply that millions of tonnes of claimed reductions in greenhouse-gas emissions are mere phantoms, she says, and potentially cast doubt over the principle of carbon trading. "In the face of these comments it is no wonder that the United States has backed away from emission trading," Filzmoser says.

The cable, written on 16 July 2008 , was sent by the US consulate in Mumbai, India, to the US secretary of state, and summarizes a discussion of the CDM involving representatives of the consulate and the US Government Accountability Office, along with Indian officials and executives of large Indian companies. At the time, 346 Indian projects had been registered with the CDM's executive board. Today, more than 720 Indian projects have been approved and have gained some 120 million tonnes' worth of carbon credits, a large fraction of the 750 million tonnes issued since 2005 (see 'Cleaning up').

Yet on the evidence of discussions at the meeting, most of the carbon-offset projects in India fail to meet the $\mathrm{CDM}$ requirements set by the UN Framework Convention on Climate Change. The cable also describes the UN's validation and registration process as "arbitrary".

Indian authorities were also criticized in the cable. All CDM projects must be validated nationally, then verified independently by an accredited firm. But the cable quotes R. K. Sethi, then chairman of the CDM's executive board and member-secretary of the Indian CDM authority in New Delhi, as admitting that the authority simply "takes the project developer at his word for clearing the additionality barrier".

"This will not invalidate carbon trading, but it does go to show that the CDM has serious flaws," says Mark Maslin, a climatologist at University College London. "In India and China, the multiple levels of governance which you need to have in place to make carbon trading work are simply not there."

Martin Hession, head of global carbon markets at the UK Department of Energy and Climate Change, and chairman of the CDM executive board, says that the critical remarks in the cable date from a time when "people were complaining a lot" about problems with the CDM. Controversies over whether specific projects reduce net emissions are still common, he says. But since 2008, the board has followed more stringent guidelines for verifying the eligibility of projects and for enhancing the overall efficiency of the scheme.

"The CDM is much more transparent and predictable than the tenor of these remarks 
> might suggest," he says. "We reject many projects in India and China because they fail to meet the required criteria, and we do in fact often get the message that project validation has become too stringent."

Others argue that the rules are still not rigorous enough. In some circumstances, the CDM may actually have encouraged the production in developing countries of the coolant chemical HFC-23, an extremely potent greenhouse gas (M. Wara Nature 445, 595-596; 2007). Critics have demanded harsher sanctions against validating companies found guilty of lax oversight, together with clearer conflict-ofinterest policies and tighter rules on what qualifies as an additional clean-development project.

International Rivers, an environmental campaigning group based in Berkeley, California, is now calling on the CDM executive board to reject the 412-megawatt Rampur hydropower project in Himachal Pradesh, India, which is awaiting CDM approval. The project could earn some 15 million carbon credits from 2012 to 2022, amounting to an estimated US\$150-million windfall for the Shimla-based

\section{CLEANING UP}

Roughly one-fifth of projects in the Clean Development Mechanism are registered in India - but most do not comply with the scheme.

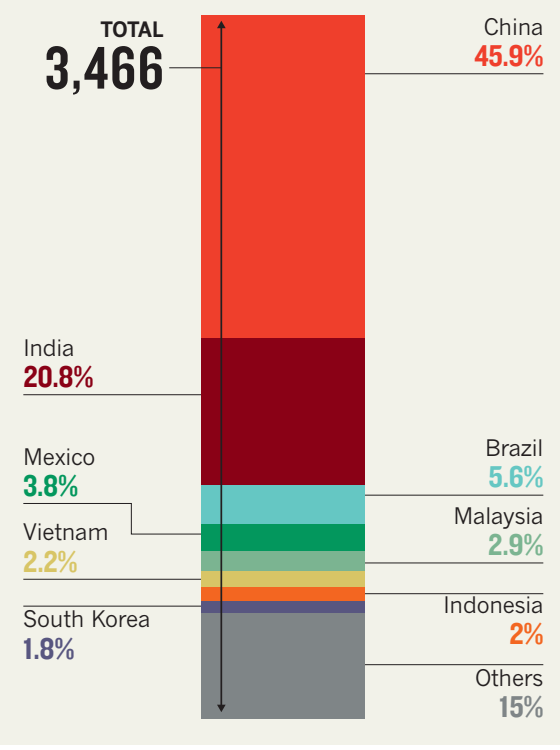

developer Satluj Jal Vidyut Nigam Limited, the group says. But the decision to finance that $\frac{4}{3}$ project was taken long before the CDM was even created, says Himanshu Thakkar, director of the Delhi-based South Asia Network on Dams, Rivers and People, clearly invalidating its application.

The company stands by its claim that the project qualifies for the CDM, and says that the Indian government approved the investment proposal for the project in 2007, when the CDM was already in place. As Nature went to press, the CDM's executive board, which met in Quito, Ecuador, this week, had not yet decided whether to approve the Rampur project.

Despite the controversy, the European Union seems determined to continue its mandatory emissions-trading system, which it sees as crucial in tackling climate change. There's little doubt about the urgency of that goal: global carbon dioxide emissions have increased by $45 \%$ since 1990 , reaching an all-time high of 33 billion tonnes in 2010, according to a report released last week by the European Commission (see page 515).

\section{Europe to map the human epigenome}

\section{DNA-modification studies get a multi-million euro boost.}

\section{BY ALISON ABBOTT}

$\mathrm{T}$ he health-research division of the European Commission launches its largest-ever project next week with a $€ 30$-million (US\$41-million) investment in understanding the human epigenome, the constellation of DNA modifications that shape how genes are expressed.

With the project, called BLUEPRINT, Europe intends to become a major player in the International Human Epigenome Consortium (IHEC), set up last year to help biologists understand how the epigenome influences health and disease.

All the cells that make up an individual originate from the same fertilized egg and share the same genome. But during development, cells acquire epigenetic changes - such as chemical modifications to DNA, and changes in the shape of its tightly coiled three-dimensional structure - that affect which genes will be active in which cells at aiven time and which will be silent.

The epigenome then remains largely stable, so that a liver, for example, remains a liver throughout life. But small parts of the epigenome change constantly as the cell responds to environmental changes. The epigenome also changes in diseases, including cancer.

The importance of the epigenome in health and disease is becoming increasingly clear. But researchers studying it have faced a big hurdle: the lack of a reliable library of highquality, quantitative reference epigenomes against which new data can be compared. Little is known, even, about how much the epigenome normally varies between individuals, or between the different cells in an individual.

Enter BLUEPRINT, which unites 41 institutions and more than 50 principal investigators across Europe who will contribute a further $€ 10$ million to the project. BLUEPRINT will provide at least 100 reference epigenomes toward the IHEC's goal of amassing 1,000 reference epigenomes by 2020 .

BLUEPRINT has chosen to focus on the blood system. This should help move discoveries quickly into the clinic, as many diagnostic tests rely on blood samples. "Blood is also what gets stored in biobanks and used for genome analysis," says BLUEPRINT coordinator
Henk Stunnenberg at the Nijmegen Center for Molecular Life Sciences in the Netherlands.

Beyond these conveniences, there was also a compelling biological rationale for the choice, he says. Unlike most tissues, blood cells are constantly renewed, so blood comprises a mix of cells at different stages of maturity. "Bloodcell epigenomes may reveal some general rules about how cells develop," Stunnenberg says.

BLUEPRINT will generate reference epigenomes from 60 different cell types, taken from the blood of healthy individuals stored in the UK's national blood bank. Each epigenome will include a full genome sequence, and genome-wide quantitative data on the occurrence and distribution of nine different epigenetic markers.

For comparison with healthy epigenomes, the consortium will produce reference epigenomes for more than 60 blood-cancer cell types. It will carry out experiments in mice to work out how much of the epigenome is heritable. The consortium also plans to generate lower-resolution epigenomes from two bloodcell types from 100 healthy people to provide a first quantitative indication of natural individual variation.

"BLUEPRINT is the first big epigenome project to be specifically created in alignment with the IHEC mission," says Peter Jones at the University of Southern California in Los Angeles, who helped to launch the IHEC. "Blood epigenomes are particularly exciting because we know an awful lot about the biology of how blood stem cells differentiate, but little about the sequence of epigenomic events involved in the processes that are going to be relevant for disease." - 